\title{
Effect of Hybrid Reinforcement on the Performance of Filament Wound Hollow Shaft
}

\author{
Mateen Tariq ${ }^{1}$, Salman Nisar ${ }^{1, *}$, Aqueel Shah ${ }^{1}$, Sohaib Akbar ${ }^{2}$, Muhammad Ali Khan ${ }^{3}$, Sohaib Zia Khan ${ }^{4}$ \\ ${ }^{1}$ Department of Industrial Manufacturing Engineering and Management, PN Engineering College, National University of \\ Sciences and Technology, PNS Jauhar, Karachi, 74500, Pakistan, \\ ${ }^{2}$ Pakistan Space and Upper Atmosphere Research Commission, Karachi Pakistan, \\ ${ }^{3}$ School of Aerospace, Transport and Manufacturing, Cranfield University, Cranfield, M43 0AL, United Kingdom, \\ ${ }^{4}$ Department of Mechanical Engineering, Faculty of Engineering, \\ Islamic University of Madinah, Madinah, PO Box 170, Kingdom of Saudi Arabia
}

\begin{abstract}
Previous studies have shown that composite materials can replace metals as the material of construction in shafts. Composite material shafts are normally made up of polymer matrix composites as they are easy to design and economical to manufacture. This paper investigates the effect of hybrid reinforcement on the performance of filament wound hollow shaft. The hybrid shafts are composed of hybrid filaments including a combination of carbon, glass and aramid fibers. The initial stage involved development and verification of FEA model in order to establish grounds for further experimentation. Afterwards, a design of experiments model was established and experiments were performed using FEA. After the design phase, the shafts were manufactured using filament winding processing technique employing suitable matrix and reinforcement systems. Lastly, the shafts were tested for torsional characteristics, hardness, density and chemical reactivity. The results showed that carbon fiber reinforcement shows best results in terms of torsional characteristics. In terms of chemical reactivity, carbon-glass hybrid reinforcement exhibited minimum degradation. Furthermore, it was also found that hybrid reinforcements containing carbon-aramid fibers showed better results in terms of density and surface hardness.
\end{abstract}

Keywords: Composite Material, Hybrid Reinforcements, Hollow shafts, Filament winding

*Corresponding author: Tel: +92(0)21 48503039

Email address: salman@pnec.nust.edu.pk 


\section{Introduction}

The quest for better material to improve engineering design has led to the development of high strength and light weight composite materials which are progressively impacting the daily life of humans. Modern research is exploiting the use of composite materials in order to design efficient systems especially in aerospace and automotive sector.

Composite materials made by filament winding technology are preferred over their metallic counterparts due to their high strength at a much lower weight. This property of filament wound composites makes them ideal in circumstances where weight saving is required such as applications for aerospace and automotive. Shafts are used to transmit the rotary load from one component to another and they are usually cylindrical in nature. Filament winding technology can be employed to manufacture shafts that are hollow and symmetrical. Previous researchers [1-5] have shown that shafts made up of composite material are advantageous to the overall efficiency of a system.

Researchers have studied the effects of hybrid fibers in a varied manner. Sevkat et al. [6] examined the effect of torsional strain-rate and lay-up sequences using hybrid fibers. Findings of the research study revealed that with the change in lay-up sequence, there is a change in torsional properties. In another research, Abu Talib et al. [7] conducted a numerical study on stacking sequence hybrid fibers with a combination of glass and carbon fibers. The researchers claimed that worst stacking sequence results in $46.07 \%$ less strength than a shaft with best stacking sequence. Among other researchers, Badie et al. [8] also investigated hybrid glass/carbon fiber shafts with changing stacking and orientation and its effect on various parameters. They concluded that an orientation angle of $45^{\circ}$ is best in order to achieve the maximum stiffness.

Composite shafts can also be manufactured using a combination of metallic and composite parts. Lee et al. [9] developed a shaft in which a combination of composite and metallic parts was utilized. The results of the study revealed that a hybrid shaft offers $75 \%$ mass reduction and $160 \%$ increase in torsional strength compared to the full metallic shaft. Mutasher [10] also examined the hybrid aluminum/composite shaft with the prediction of torsional strength using analytical techniques. The study inferred that an increase in a number of composite layers leads to an increase in torsional strength with a compromise on weight.

Apart from filament winding technology, few researchers have used alternate techniques to manufacture the shafts. Capela et al. [11] utilized molding technique to fabricate all carbon fiber tubular shaft by vacuum bagging to investigate the effects of torsional stress. The study showed that fatigue and static strength decrease with an increase in shear stress during the torsional moment. Additionally, Pater et al. [12] produced a hollow drive shaft by using rotary compression. The study claimed that this process is an alternate to the fabrication of composite shafts from conventional methods.

Apart from torsional properties, Shokrieh et al. [13] and Bert et al. [14] analyzed shear buckling properties of composite shafts by applying tensile loads. The research study found that the natural frequency of composite shaft decreases with an increasing torque. Among other factors that affect the buckling torque is the stacking sequence of composite laminates.

Adding various additives or natural fibers can also alter the performance of composite shafts. Misri et. al. [15] fabricated composite shafts using natural fiber such as kenaf and employing the process of filament winding. The torsional test on fabricated samples found that sample with kenaf fiber and aluminum reinforcement have the highest torsional strength and the highest degree of rotation. Siddiqui et al. [16] studied the effect of carbon nanotubes on torsional properties of carbon fiber composites. Samples were fabricated using various 
percentages of CNTs. The results indicated that test specimens with $0.5 \%$ CNT showed $17 \%$ increase in torsional modulus and 19\% increase in torsional strength.

Previous researchers have [6-8] conducted studies on hybrid shafts using more than one type of reinforcement. The term hybrid shafts referred to fabrication technique using multiple type of reinforcement layers. However, no study has been conducted utilizing hybrid reinforcement in a single layer to fabricate filament wound hollow shafts. This study incorporates multiple type of fibers within a single layer. Moreover, Glass and aramid fibers are known for their low cost and high flame resistance respectively and hence a hybrid fiber with carbon fiber not only provides strength but also add up other advantages. This paper investigates the effect of hybrid reinforcement on the performance of hollow shafts. The purpose of the research is to deduce information on hybridization of shafts as compare to pure carbon fiber counterparts. The research explicitly provides an explanation on effects incurred by hybrid fiber reinforcements including carbon-glass and carbon-aramid hybrids. This investigation bridges the gap between the use of hybrid fibers for specialized application such as aerospace and marine. Furthermore this research enhances the knowledge in use of hybrid reinforcements as suitable material for multipurpose application as provided by each incorporated fiber.

The shafts were first modeled through finite element commercial based software ABAQUS. After verification of the model by comparing three pilot experimental and simulated results, the design of experiments was performed in order to check various combinations. The rationale for performing design of experiments was to study variables such as lamination sequence and layer type as manufacturing of each design is not cost effective. Afterwards, the design of shaft based upon an optimal combination of layup sequence and layer type was selected and manufactured using filament winding technology. Manufactured shafts were then tested on the torsional testing machine to examine torsional characteristics. Furthermore, shafts were also tested for supplementary properties such as surface hardness, chemical reactivity, and density. Another factor of the study was the effect of a hot and cold curing resin.

\section{Design and analysis}

The approach for design and analysis for this study is based on three phases. The first stage involves the development of a model and its validation while the second phase comprises of the design of experiments. The third stage includes the selection of shafts for manufacturing and testing based on the optimal design provided by design of experiments.

\subsection{Model generation and validation}

For finite element analysis, ABAQUS software version 6.0 was used. For composite materials, structures may be assumed as composed of several layers and each layer have orthotropic properties. For the study, CAD model was developed using part generation module in ABAQUS.

For analysis purpose, a twisting moment was generated within the material. The boundary conditions coincided with the actual experimental settings. One end of the shaft was fixed for movement in all degrees of freedom while another end was assigned to a rotation of 5 degrees. Assumptions of the FE model includes the use of orthotropic material model and each reinforcement holds half the volume in hybrid shafts. Displacement in rotation direction develops twisting moments which causes stress throughout the material. The model was developed using composite continuum shell element S8R. Mesh sensitivity analysis was performed on the developed model for validation of the mesh. The values of mesh size and their response value of stress are given in Table 1 . Figure 1 shows a meshed model used for the study along with boundary conditions whereas Figure 2 shows a deformed model.

Part geometry was a simple hollow cylinder with a length of $300 \mathrm{~mm}$ and a diameter 
$20 \mathrm{~mm}$. The outer diameter of the part is defined by thickness and the number of laminas as per design, given in Table 2.

Table 1: Mesh sensitivity analysis

\begin{tabular}{|c|c|c|c|}
\hline SNo & $\begin{array}{c}\text { Approximate } \\
\text { Element Size } \\
(\mathbf{m})\end{array}$ & $\begin{array}{c}\text { Created } \\
\text { Elements }\end{array}$ & $\begin{array}{c}\text { Calculated } \\
\text { Stress } \\
(\mathbf{P a})\end{array}$ \\
\hline 1 & 0.1 & 160 & $7.85 \mathrm{E}+07$ \\
\hline 2 & 0.01 & 360 & $7.74 \mathrm{E}+07$ \\
\hline 3 & 0.009 & 429 & $7.66 \mathrm{E}+07$ \\
\hline 4 & 0.008 & 570 & $7.53 \mathrm{E}+07$ \\
\hline 5 & 0.007 & 731 & $7.42 \mathrm{E}+07$ \\
\hline 6 & 0.006 & 1000 & $7.28 \mathrm{E}+07$ \\
\hline 7 & 0.005 & 1440 & $7.14 \mathrm{E}+07$ \\
\hline 8 & 0.0049 & 1440 & $7.15 \mathrm{E}+07$ \\
\hline 9 & 0.0048 & 1575 & $7.12 \mathrm{E}+07$ \\
\hline 10 & 0.0046 & 1690 & $7.12 \mathrm{E}+07$ \\
\hline
\end{tabular}

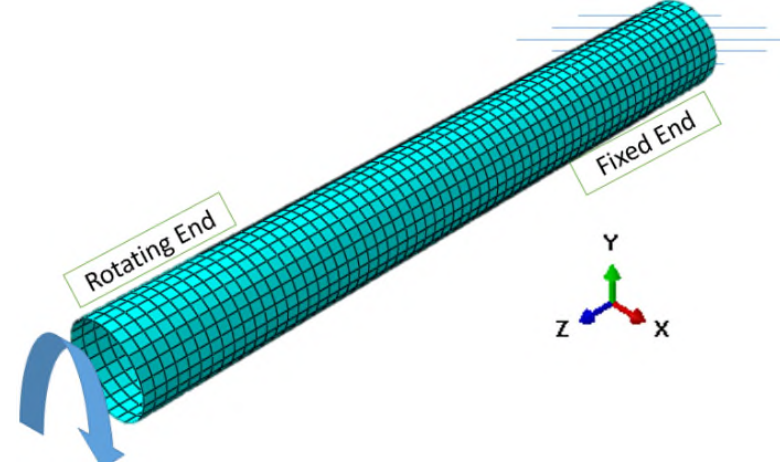

Figure 1: CAD representation of Mesh Model

Developed CAD model replicates actual samples fabricated for Realtime testing. As Torque depends upon length and diameter of the shaft, similar CAD model was used to perform each 378 experiments in order to achieve comparative results.

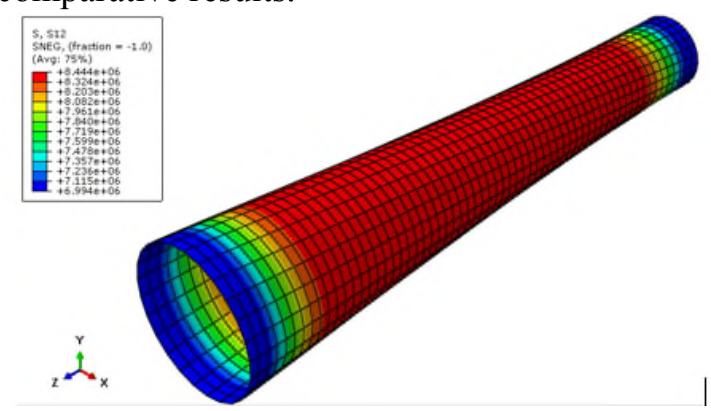

Figure 2: Deformed Model showing Stressed Areas
Orthotropic material type for composite materials was chosen for the material design. Material properties used for simulation purposes are given in Table 3 .

Initially, three different FE models were developed and validated through experiments. Helix layer for FE models is defined as $\pm 45^{\circ}$. The sequence is selected while keeping in mind alteration of layers and studying effect of addition of single layer. The validation is a necessary part of all the later experiments and it will depend upon same simulation design.

The torque was calculated from equation [17] as below; while max stress value was obtained through FE analysis.

$$
\text { Torque }=\frac{\pi}{16} \sigma_{\max } \frac{\left(D^{4}-d^{4}\right)}{D}
$$

where,

$\sigma_{\max }=$ Maximum Stress

$\mathrm{D}=$ Outer Diameter

$\mathrm{d}=$ Internal Diameter

Manufacturing of shafts was performed using a two axis filament winding machine. Carbon fiber bobbins or spools were weighed and fixed on the spool creel. Carbon fiber from each spool was delivered through resin bath which contained series of transportation rollers. The resin on rotating drum was controlled by doctors' blade to control resin delivery. Shafts were allowed to cure at the room temperature for 24 hrs. After complete curing, shafts were removed from the mandrel and faced to get finishing. Fabricated carbon fiber hollow shafts are shown in Figure 3.

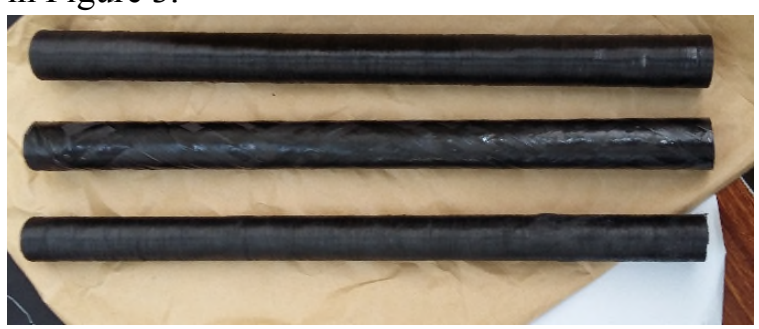

Figure 3: Manufactured shafts for validation

Manufactured shafts were then subjected to torsional test and the results were compared with simulated values. Results, as obtained from FEA model and experiments, were compared. 
Table 2: Design of Experiments

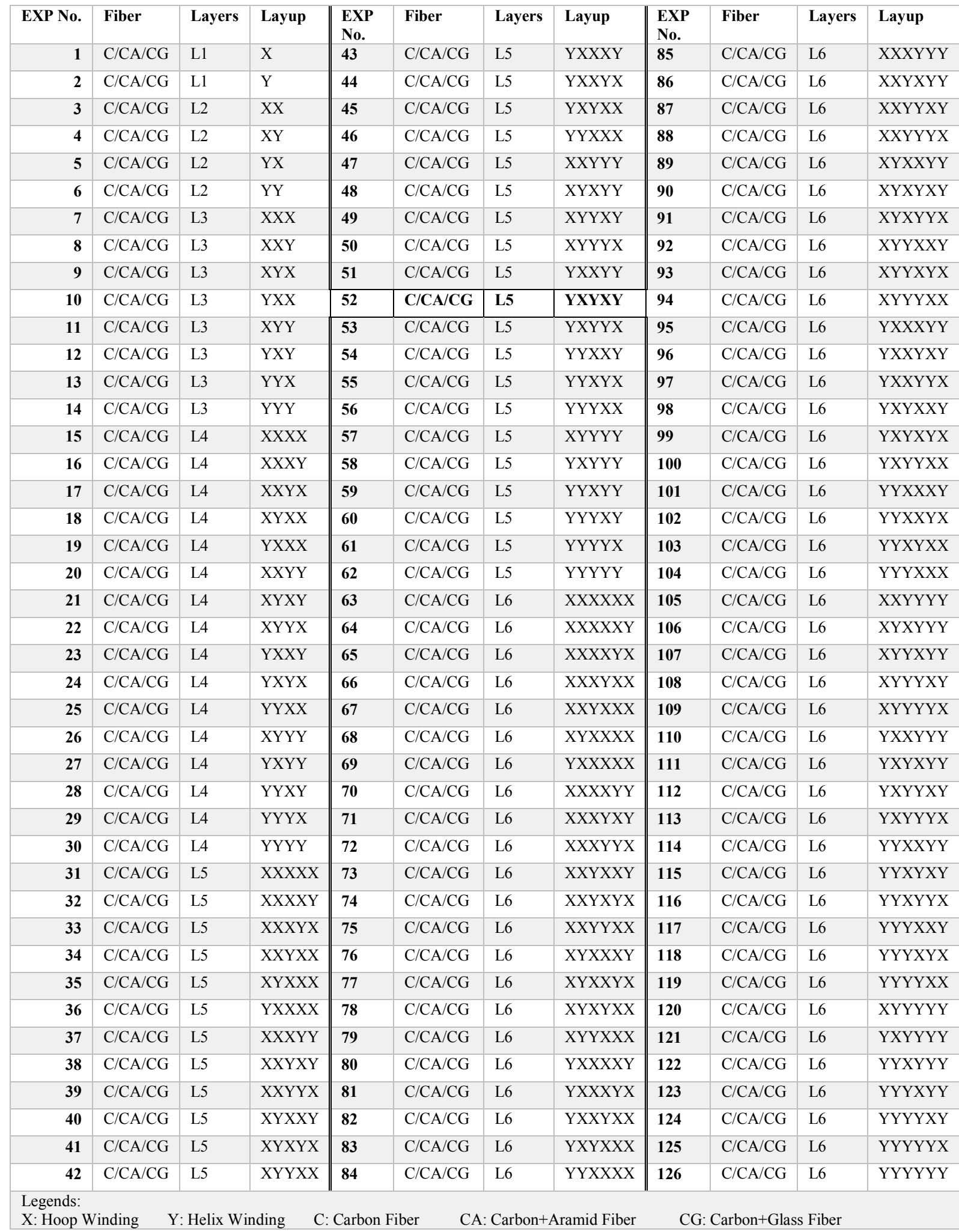


Table 3: Material Properties

\begin{tabular}{|l|c|c|c|c|c|c|c|}
\hline & E1 (GPa) & E2(GPa) & Poison's Ratio & G12(GPa) & G23(GPa) & G31(GPa) & Density (gcm $\mathbf{g c h}^{-3}$ \\
\hline Carbon/ Epoxy & 34.8 & 6.88 & 0.33 & 2.72 & 2.89 & 2.8 & 1.33 \\
\hline Glass/ Epoxy & 10.0 & 6.68 & 0.27 & 2.17 & 2.63 & 2.63 & 1.74 \\
\hline Aramid/ Epoxy & 20.4 & 8.90 & 0.31 & 1.64 & 3.03 & 1.64 & 1.23 \\
\hline
\end{tabular}

Table 4 provides description of FE models for validation. It includes 3, 4 and 5 layers with different layup sequence. The sequence selected for validation elaborates significance of adding a hoop or helix layer on overall properties. Hence with the selected sequence effect of a single layer is explained. Comparison was done to find conformance of the model to actual results. Figure 4 shows a comparison of maximum torque values obtained through experimentation and FE simulation. Also, the percentage difference of experimental and simulated values is shown in Figure 4. Deviation from actual results is due to human and environmental factors such as operator's skills, temperature, and humidity. Table 4: Detail of FE Models for validation

\begin{tabular}{|l|l|l|l|}
\hline $\begin{array}{l}\text { Sample } \\
\text { ID }\end{array}$ & Matrix & Fiber & $\begin{array}{l}\text { Layup } \\
\text { Sequence and } \\
\text { Layer Type }\end{array}$ \\
\hline Val_A & Epoxy & $\begin{array}{l}\text { Carbon } \\
\text { Fiber }\end{array}$ & $\begin{array}{l}- \text { Hoop(B)* } \\
- \text { Helix } \\
- \text { Hoop(T)** }\end{array}$ \\
\hline Val_B & Epoxy & $\begin{array}{l}\text { Carbon } \\
\text { Fiber }\end{array}$ & $\begin{array}{l}- \text { Hoop(B)* } \\
- \text { Helix } \\
- \text { Hoop } \\
- \text {-Helix(T)** }\end{array}$ \\
\hline Val_C & Epoxy & $\begin{array}{l}\text { Carbon } \\
\text { Fiber }\end{array}$ & $\begin{array}{l}\text {-Hoop(B)* } \\
- \text { Helix } \\
- \text { Hoop } \\
- \text {-Helix } \\
- \text {-Hoop (T)** }\end{array}$ \\
\hline
\end{tabular}

* Bottom Layer

**Top Layer

The results showed a fair correlation between experimental and simulated results. Therefore, while keeping in mind the environmental conditions and unknown variables such as mixing of resin and human interventions, the deviation may be treated as minor and the model is considered as satisfactory for further experimentation. Moreover, deviation from results is also caused by FEA assumptions including boundary conditions such as fixing one end and applying rotational force on other face. It is observed that stiffness values followed same trend as thickness. Val_C with maximum thickness showed maximum stiffness value where as Val_A with minimum thickness showed minimum stiffness value.

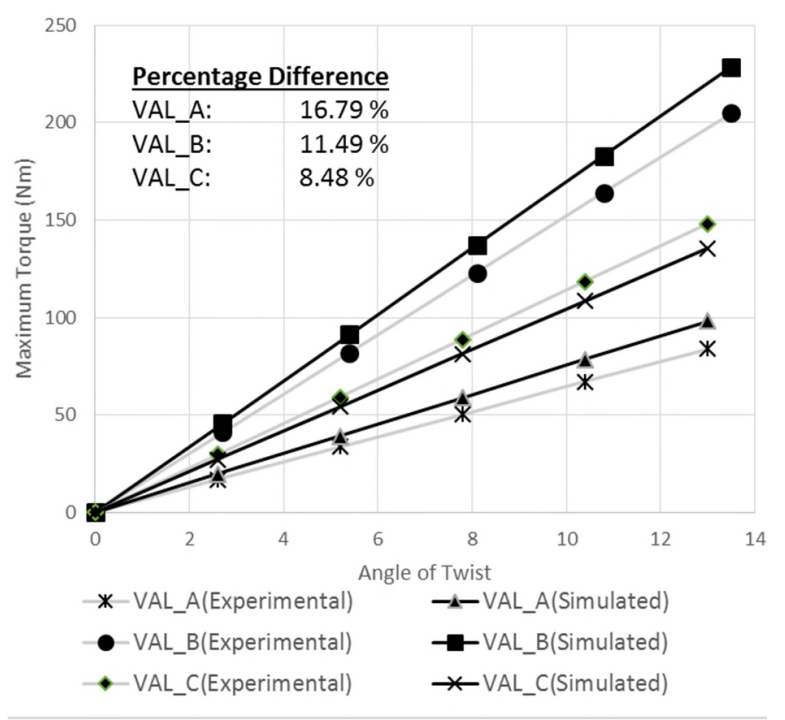

Figure 4: Experimental vs. Simulation results

\subsection{Design of experiments}

For the design of experiments, several factors were considered which are given below:

- Fiber type

- Layup sequence and layer type

- Number of layers

Other factors such as matrix material and orientation angle were kept constant. By 
combining all the factors, a design of experiments was formed. A mixed Taguchi model orthogonal array L18 comprising of 2 factors and 6 columns was developed using statistical software Minitab version 17. Table 5 shows levels for mixed Taguchi model L18; with 3 levels for fiber type and 6 levels for a number of layers. A total of 126 experiments were developed for each reinforcement type and as there were three types a final design of 378 experiments was established. The angle of helix winding was fixed at $45^{\circ}$.

Table 5: Levels of Taguchi L18 Model

\begin{tabular}{ccc}
\hline Level & \multicolumn{2}{c}{ Factors } \\
\hline & No. of Layers & Fiber Type \\
\hline 1 & 1 & Carbon \\
2 & 2 & Carbon+Aramid \\
3 & 3 & Carbon+Glass \\
4 & 4 & \\
5 & 5 & \\
6 & 6 & \\
\hline
\end{tabular}

\subsection{Selection of shafts for manufacturing}

After performing design of experiments and running the model for all the combinations, it is found that helix reinforcement layers offer more resistance than hoop reinforcement layers. Adding helix layer rather than hoop layer enhances the value of torque to about $75 \sim 85 \%$. Moreover, helix layer can provide 30 40\% more torsional strength if it is located on surfaces compared to when located between thickness. Furthermore, an alternate sequence of layers results in 30 40\% more torque compared to agglomerated layers in the layup. While using hybrid fibers, pure carbon fiber shafts offered maximum torque, while carbon-aramid showed better results than a carbon-glass hybrid in helix loaded layup sequence and vice versa for hoop loaded layup.

While keeping in view all the output characteristics, an optimum design of shaft was selected. The design incorporates helix layer on the top and bottam surfaces. Moreover, as results revealed that layers should be in alternating form, the selected design also possess two type of layers in an alternate fashion. Also, the total number of layers were selected as 5 to observe symmetry and avoid excessive weight. Experiment number 52 as given in Table addresses all the criteria, hence it was selected for further manufacturing. Manufacturing of shafts

\subsection{Material}

As the study is based on polymer matrix composites, major materials encompasss reinforcements or fibers and matrix or resin. The matrix used was epoxy in nature and two different grades were used. For room temperature curing resin design, Epolam 2040 of Axson Technologies was used. The resin was supplied with a hardener and ratio of resin to hardener was 100:32. It was observed that the resin displayed average gel time of 80 minutes. Another type of resin which was characterized as high temperature curing resin was Araldite 564 of Huntsman Company. This resin was also two components in nature with the ratio of resin to hardener set at 100:35. Three type of reinforcements was used in the study including carbon, glass and aramid fibers. All type of fibers were supplied in tow form having external unwinding. For making hybrid reinforcements, one spool of each was used to achieve an even percentage.

\subsection{Fabrication of samples}

Fabrication of samples was carried on a filament winding machine. The machine was computer operated with the numerical control system. Moreover, two degrees of freedom was utilized for making patterns of winding for fabricated samples.

The mandrel is an important component in manufacturing via filament winding technology. For fabrication of samples, a mild steel mandrel was used. For surface preparation firstly a layer of Poly Tetra Floro-Ethylene (PTFE) release film was pasted on the mandrel and then a lubrication agent was applied evenly over the surface. The 
lubricating agent allowed easy retrieval of the shaft. Figure 5 shows mandrel mounted on filament winding machine before manufacturing.

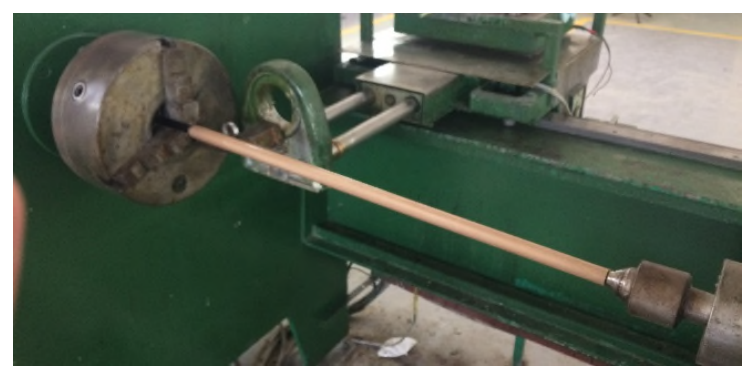

Figure 5: Mandrel mounted on machine

The machine was first programmed for helix and hoop winding using the inbuilt software. Furthermore, before wet winding, a dry run of fibers was performed to check conformance of uploaded pattern. After verification of pattern, the machine was operated for wet winding. The process included impregnating fibers from two spools in a resin bath and then winding them over a mandrel. The fibers were transported to mandrel while in a stressed state in order to achieve compaction in part. For hybrid fibers, one spool of each type was used. The manufacturing was done layer by layer as per design. The resin was provided in a resin bath and was mixed in batches of $500 \mathrm{~g}$. Figure 6 depicts a winding of helix layer with carbon-aramid reinforcement, whereas Figure 7 shows a hoop winding in progress.

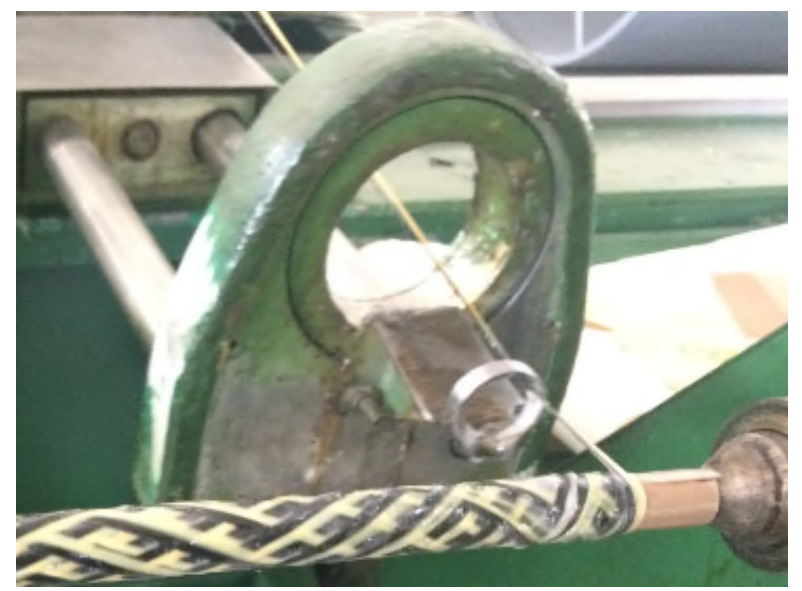

Figure 6: Winding of helix layer

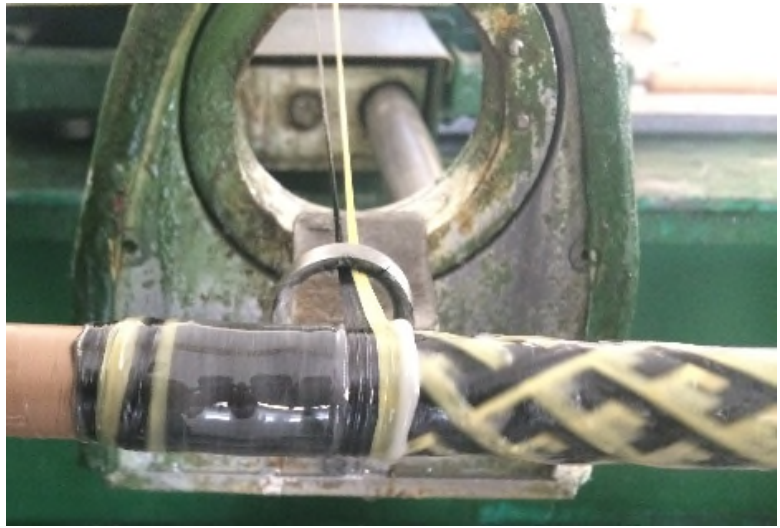

Figure 7: Winding of hoop layer

After completion of winding, the part was either allowed to cure at room temperature or was supplied to a curing oven for further processing. The oven curing was performed by exposing the manufactured samples to $150^{\circ} \mathrm{C}$ and holding for two hours. Figure 8 illustrates all the shafts manufactured using the process.

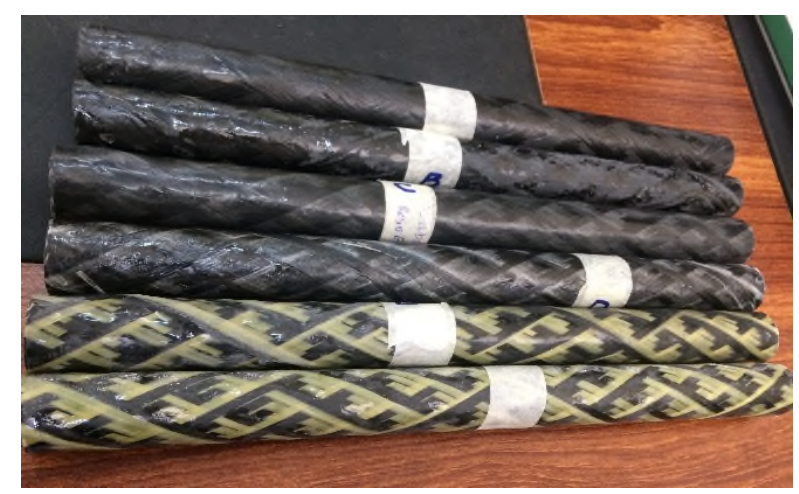

Figure 8: Cured Shafts

\subsection{Detail of shafts}

Selection of design was made from the design of experiments as mentioned in Section 2.3. The shafts used same processing technique i.e. filament winding except for curing conditions. As another objective of the study was to observe the effect of curing conditions of resin, each design was repeated for high and room temperature curing the resin. Table 6 gives detail of fabricated shafts. 
Table 6: Detail of shafts

\begin{tabular}{|c|c|c|c|}
\hline Code & Reinforcement & Matrix & $\begin{array}{c}\text { Curing } \\
\text { Conditions }\end{array}$ \\
\hline Exp-A & Carbon Fiber & $\begin{array}{c}\text { Epolam } \\
2040\end{array}$ & $\begin{array}{c}\text { Room } \\
\text { Temperature }\end{array}$ \\
\hline Exp-B & Carbon Fiber & $\begin{array}{c}\text { Araldite } \\
564\end{array}$ & $150^{\circ} \mathrm{C}$ \\
\hline Exp-C & $\begin{array}{c}\text { Carbon Fiber }+ \\
\text { Glass Fiber }\end{array}$ & $\begin{array}{c}\text { Epolam } \\
2040\end{array}$ & Room \\
\hline Exp-D & $\begin{array}{c}\text { Carbon Fiber }+ \\
\text { Glass Fiber }\end{array}$ & $\begin{array}{c}\text { Araldite } \\
564\end{array}$ & $150^{\circ} \mathrm{C}$ \\
\hline Exp-E & $\begin{array}{c}\text { Carbon Fiber }+ \\
\text { Aramid Fiber }\end{array}$ & $\begin{array}{c}\text { Epolam } \\
2040\end{array}$ & Room \\
\hline Exp-F & Carbon Fiber + & Araldite & $150^{\circ} \mathrm{C}$ \\
& Aramid Fiber & 564 & \\
\hline
\end{tabular}

\section{Testing}

\subsection{Torque}

As torsional performance is based on the amount of applied torque, shafts were tested for maximum torque they endure until rupture. Torque was calculated using a torsional testing machine utilizing ASTM E-143. The machine's workbench had two heads between which the shaft was mounted. One end of the shaft was fixed, whereas rotation was applied to the other end. The module on rotating head calculated applied torque and presented value on the screen. The inputs provided for experiments included length and diameters of the shaft. Figure 9 shows a shaft mounted in a torsional testing machine.

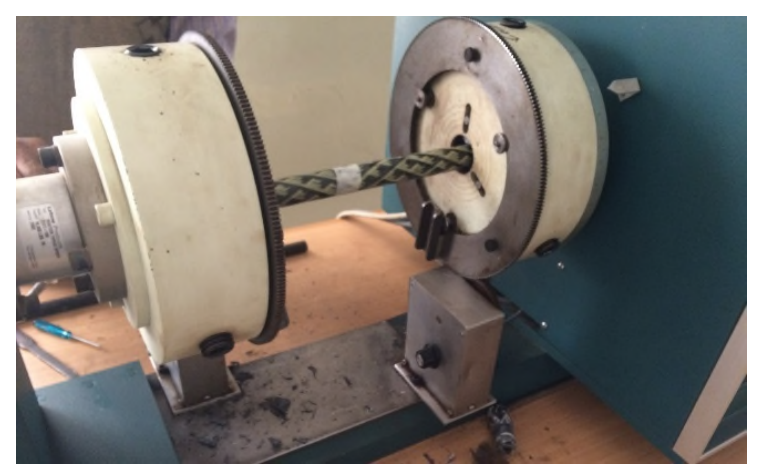

Figure 9: Torsional Testing Machine
The machine used for torsional testing provided maximum torque as the output. The value of maximum torque was obtained before a rupture as once a crack has been initiated torque decreases. Figure 10 highlights a ruptured shaft showing fiber breakage.

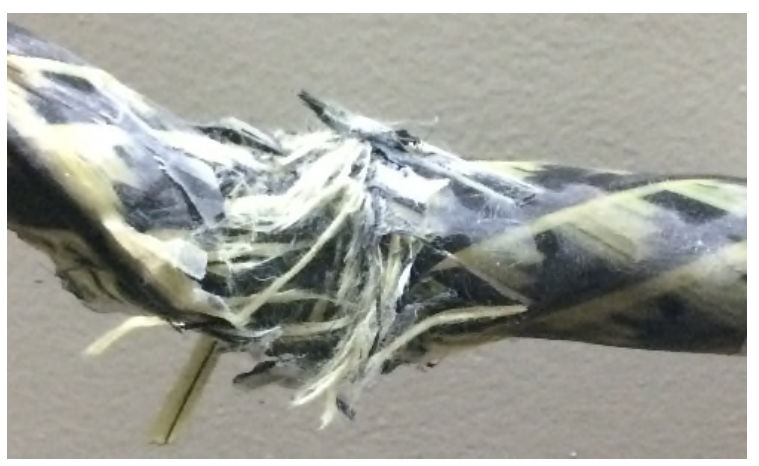

Figure 10: Ruptured Shafts

\subsection{Chemical reactivity}

As shafts are used widely in marine applications, resistance to corrosion and saline water is crucial. Chemical tests uses relative weight loss technique for determining reactivity [18]. The behavior of fabricated shafts was investigated using brine solution. The solution containing approximately $3.5 \%$ salt was prepared and small samples of fabricated shafts were submerged in it. The samples were weighed before submerging and extracted after one week and were weighted again. Weight loss gives the extent of chemical reaction as it directly relates reactivity with a brine solution. Figure 11 illustrates submerged samples.

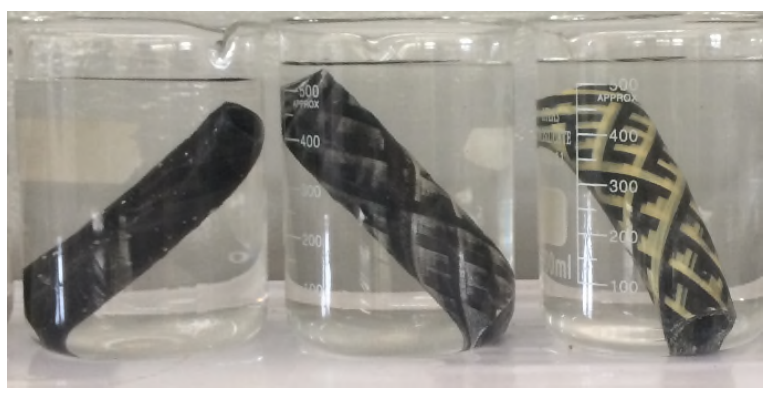

Figure 11: Submerged samples in brine solution

For investigating chemical reactivity, another test was performed using the acidic medium. A solution of $98 \% \mathrm{H}_{2} \mathrm{SO}_{4}$ was prepared 
and samples were submerged in it. The samples remained submerged for two hours to measure the rate of deterioration. With the observed rate of degradation, longer exposure may result in the complete dissolution of samples. The initial and final weight of samples were noted. The weight loss directly relates the degradation through acid reactivity. Figure 12 shows samples of shafts submerged in acidic medium.

\subsection{Hardness}

Another test performed on the shaft was hardness testing. Hardness values were obtained using Vickers hardness testing machine utilizing ASTM E-384. Samples were mounted on a bed and an indentor was pressed with calculated force against the surface. The resistance to indentation was recorded and further correlated with the hardness value.

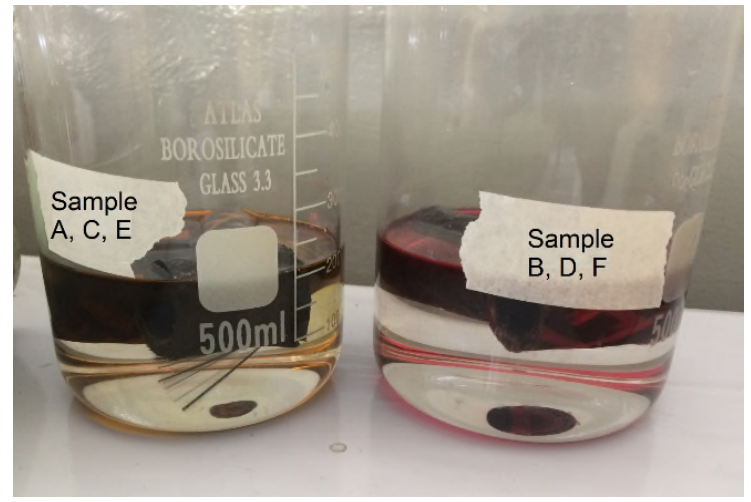

Figure 12: Submerged samples in acid solution

\subsection{Density}

Aerospace applications demand materials with high strength and low weight, hence density is an important characteristic when selecting materials for aerospace applications. For this study, fabricated samples were tested for density using water displacement method (ASTM D79213). The samples were weighted first and then submerged in water. The water displaced by submerging equals the volume of samples and hence density can be calculated. The volume was measured using a graduated cylinder.

\section{Results and Discussion}

\subsection{Torsional Characteristics}

Torsional characteristics are prime performance characteristics of a shaft and hence the manufactured shafts were tested for torsion. Torsional strength is the amount of torque a shaft exhibits before rupture. Apart from torsional strength, torsional resilience and torsional stiffness were also calculated for all shafts. Torsional resilience is given by Equation 2 [18] as below,

Torsional Resilience $=\frac{\sigma_{\max }^{2}}{4 G} \frac{\left(D^{2}-d^{2}\right)}{D^{2}} \times V$

where,

$\sigma_{\max }=$ Maximum Stress

$\mathrm{D}=$ Outer Diameter

$\mathrm{d}=$ Internal Diameter

$\mathrm{G}=$ Modulus of Rigidity

$\mathrm{V}=$ Volume

Resilience defines as the energy absorbed while force is applied on a material up to its elastic limit. The value of resilience dictates the ability to ingress applied energy. Torsional resilience is closely related to torsional stiffness as both qualities dictate the ability of a shaft to resist deformation on the applied rotational force. Torsional resilience is the amount of energy a shaft absorbs while rotational forces are applied to it. On the other hand, stiffness values define the ability to resist deformation. This value is critical as it directly relates to the dimensional changes occurred in a material when force is applied. Torsional stiffness is the ability of a shaft to resist deformation on the applied rotational force. It is given by the ratio of torque to the angle of a twist as in Equation 3 [18].

$$
\text { Torsional Stiffness }=\frac{\text { Torque }}{\text { Angle of twist }}
$$


Torsional characteristics exhibited by fabricated samples are given in Table 7.

Table 7: Results of torsional characteristics

\begin{tabular}{|l|c|c|c|c|}
\hline $\begin{array}{c}\text { Sample } \\
\text { Code }\end{array}$ & $\begin{array}{c}\text { Torque } \\
\mathbf{( N m )}\end{array}$ & $\begin{array}{c}\text { Angle of } \\
\text { Twist } \\
\text { (deg) }\end{array}$ & $\begin{array}{c}\text { Torsional } \\
\text { Stiffness } \\
(\mathbf{N m} / \mathbf{R a d})\end{array}$ & $\begin{array}{c}\text { Torsional } \\
\text { Resilience } \\
\mathbf{( J m}^{-3} \mathbf{)}\end{array}$ \\
\hline Exp_A & 201 & 3.41 & 3382 & 40.61 \\
\hline Exp_B & 167 & 3.03 & 3161 & 29.99 \\
\hline Exp_C & 113 & 2.80 & 2310 & 18.79 \\
\hline Exp_D & 96 & 2.62 & 2096 & 14.95 \\
\hline Exp_E & 148 & 3.17 & 2673 & 27.86 \\
\hline Exp_F & 136 & 3.16 & 2461 & 25.55 \\
\hline
\end{tabular}

A graphical comparison of shafts made up of room temperature cured resin is given in Figure 13 and Figure 14 shows a comparison of high temperature cured shafts. By analyzing values of maximum torque, it is found that shafts with pure carbon fiber reinforcement exhibit maximum torque as compared to hybrid shafts. Values are approximately $43 \%$ more than carbonglass hybrid shafts and $18 \%$ more than carbonaramid hybrid shafts. Shafts with carbon-aramid reinforcement showed approximately $23 \%$ higher values than carbon-glass hybrid shafts. As glass fiber exhibits the lowest strength among the fiber used, the same is attributed to low torsional strength.

In terms of curing condition of resin, room temperature cured shafts showed $17 \%, 15 \%$ and $8 \%$ more torque for carbon, carbon-glass, and carbon-aramid respectively, as compared to hot-curing resin. Torque values of hot-curing resin are less than that for room temperature curing resin because high-temperature curing promotes enhanced polymerization. This enhanced polymerization directly relates to interphase bonding of matrix and reinforcement hence, low values dictates less bonding.

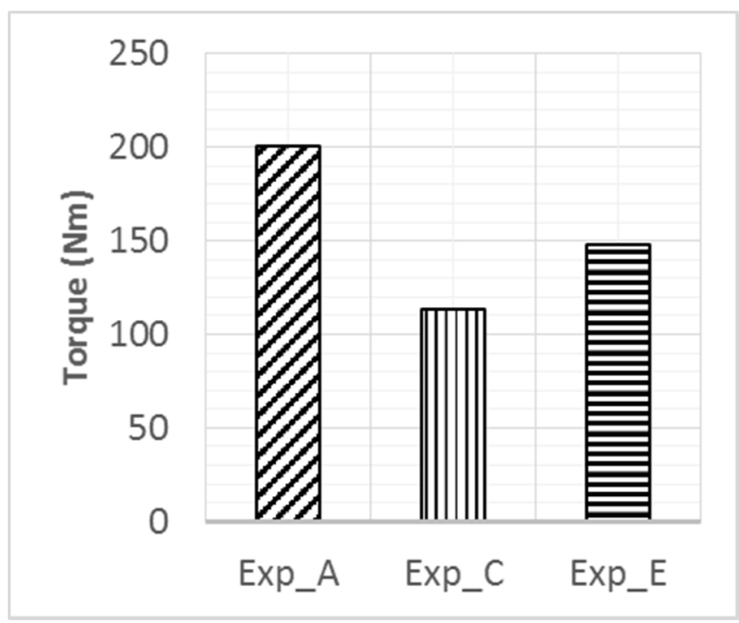

Figure 13: Torsional Strength (Room Temperature Cured)

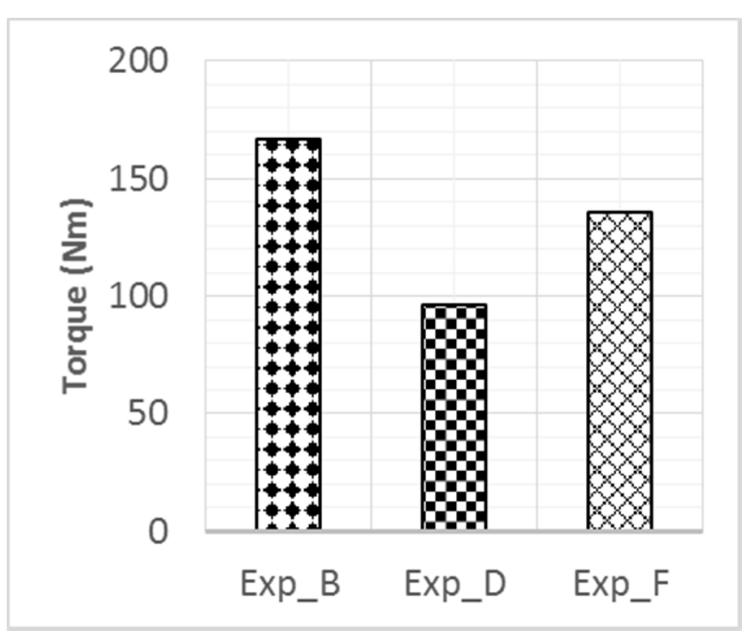

Figure 14: Torsional Strength (High-Temperature Cured)

Stiffness of a shaft depends inversely on angle of twist, figure 15 and figure 16 shows torque vs angle graphs. Furthermore Figure 17 and Figure 18 show graphical illustrations of a comparison of torsional stiffness for room temperature and a comparison of torsional stiffness for high temperature cured shafts, respectively. By analyzing values of torsional stiffness, it is evident that pure carbon fiber 
exhibits stiffness values $32 \%$ more than carbonglass hybrid shafts and $20 \%$ more than carbonaramid hybrid shafts. Moreover, shafts with carbon-aramid reinforcement showed approximately $13 \%$ higher values than carbonglass hybrid shafts. As stiffness depends upon the deformation, carbon fiber is stiffer than other fibers, hence high values of carbon fiber shafts are attributed to it.

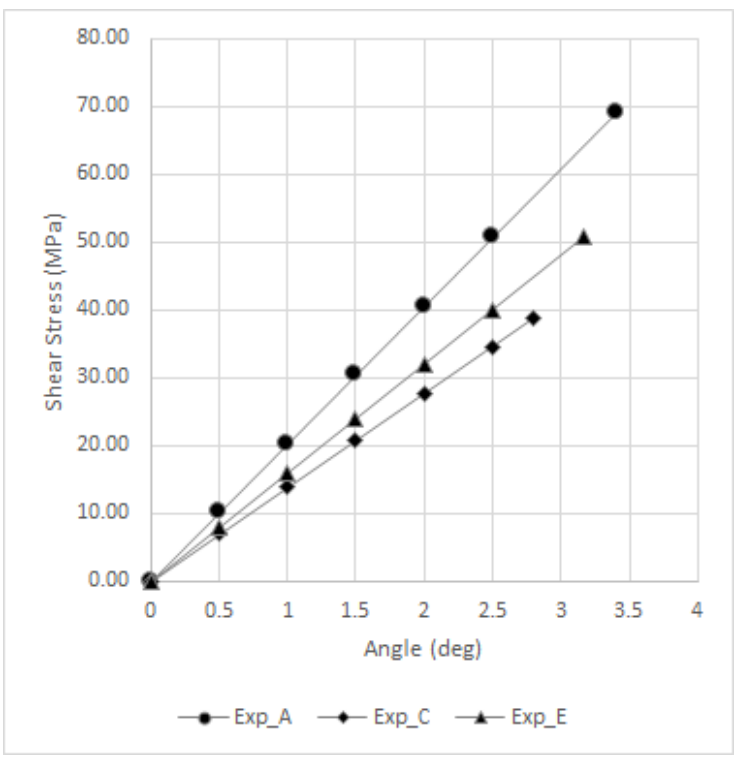

Figure 15: Shear Stress vs Angle of twist (Room Temperature Cured)

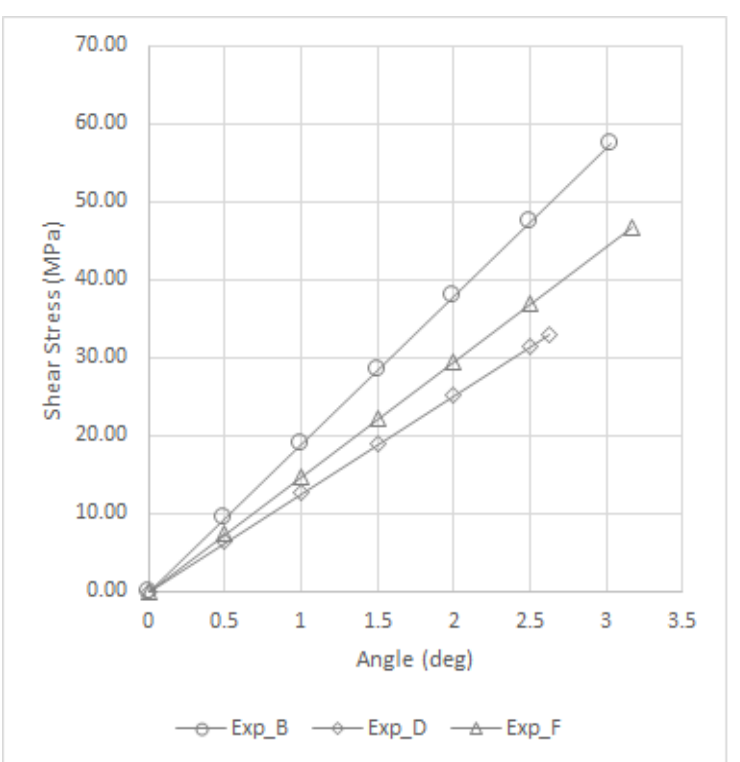

Figure 16: Shear Stress vs Angle of twist (High Temperature Cured)
Room temperature cured shafts showed $6 \%$, $9 \%$ and $8 \%$ more values for carbon, carbonglass, and carbon-aramid, respectively compared to hot-curing resin. The percentage difference for stiffness is low as compared to strength. Hence high-temperature curing resin offers similar resistance to deformation as room temperature curing resin as both belong to the same family of polymers i.e. epoxy.

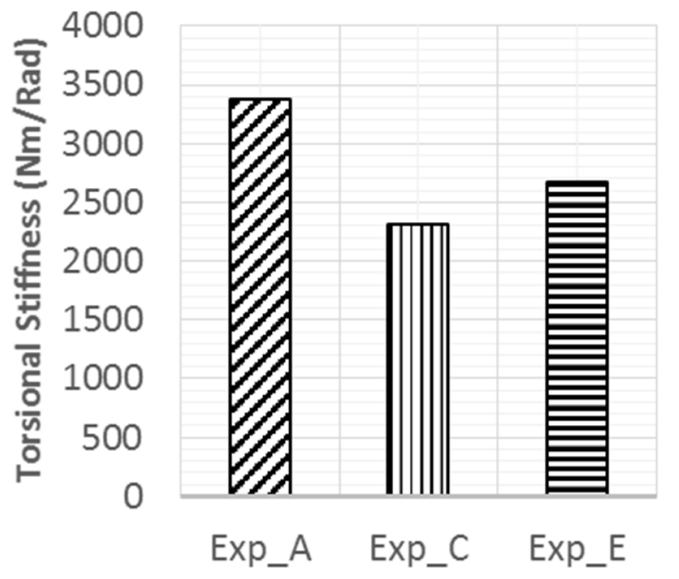

Figure 17: Torsional Stiffness (Room Temperature Cured)

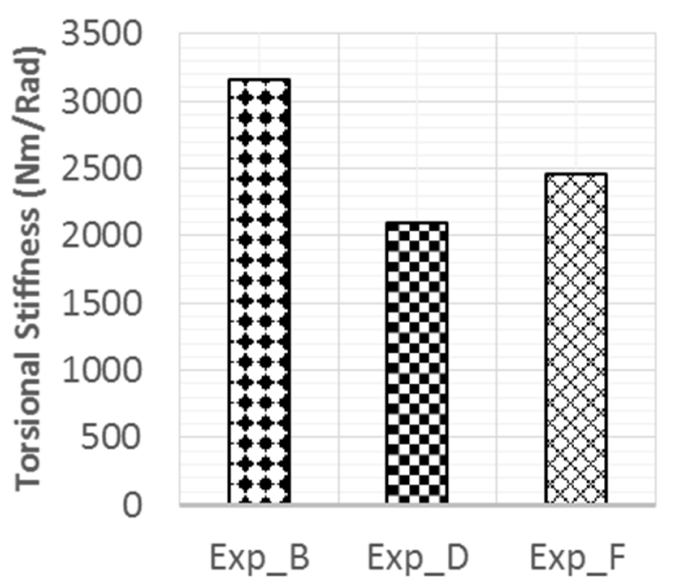

Figure 18: Torsional Stiffness (High-Temperature Cured) 


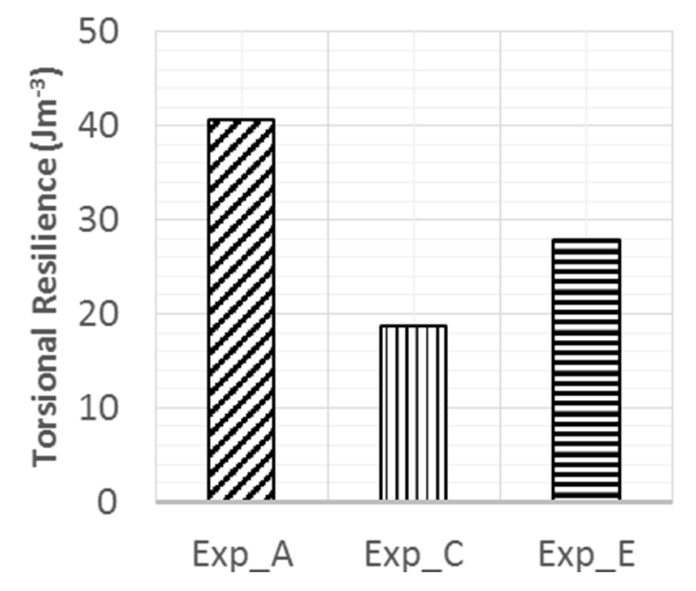

Figure 19: Torsional resilience (Room Temperature Cured)

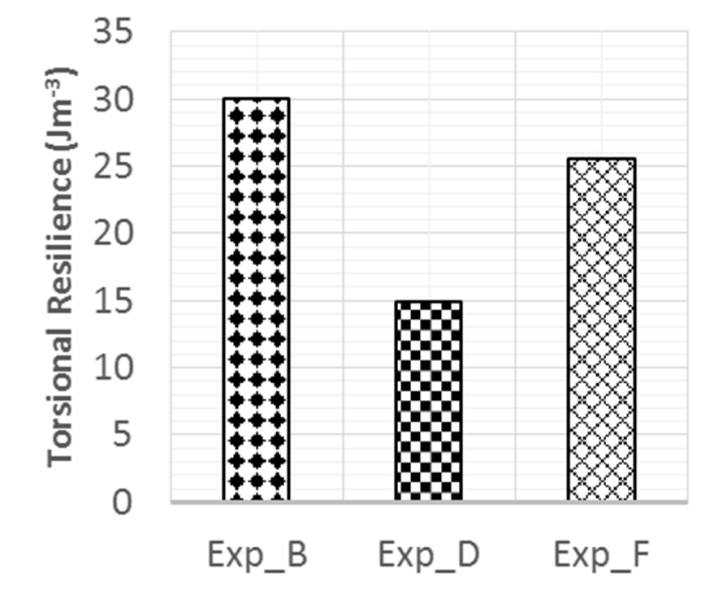

Figure 20: Torsional resilience (High-Temperature Cured)

Figure 19 and Figure 20 depicts a comparison of torsional resilience values for room temperature cured and a comparison of torsional resilience values for hot cured resins, respectively. The results showed that pure carbon fiber shafts show 53\% more resilience than carbon-glass hybrid shafts and $31 \%$ more than carbon-aramid hybrid shafts due to the high strength of carbon fibers. Shafts with carbonaramid reinforcement showed approximately $32 \%$ higher values than carbon-glass hybrid shafts. The percentage difference for resilience is much greater than stiffness and strength values. Carbon fiber possesses the highest strength as compared to other fibers, hence shafts with pure carbon fiber reinforcements show higher values of resilience than others.

Furthermore, with respect to comparison via curing condition of resin, room temperature cured shafts showed $26 \%, 20 \%$ and $8 \%$ more values for carbon, carbon-glass, and carbon-aramid respectively compared to hot-curing resin. The percentage difference is high because of the decreased strength of high temperature cured resin. The percentage difference for carbonaramid shafts is much lower as aramid fibers offer more toughness and their values are less affected by the matrix system.

\subsection{Chemical Reactivity}

Supplementary testing enhances the knowledge to use the shafts in specialized applications such as marine, aerospace and automotive. Table 8 shows numerical values of supplementary results. The percentage weight loss in brine solution is not provided as it was observed to be zero.

An acidic environment is considered as extremely harsh and degrading. Hence for applications where there is an extremely harsh environment in terms of $\mathrm{pH}$, test results for degradation in the acidic environment may be considered.

Table 8: Supplementary results

\begin{tabular}{|c|c|c|c|}
\hline $\begin{array}{c}\text { Sample } \\
\text { Code }\end{array}$ & $\begin{array}{c}\text { Acid } \\
\text { Weight } \\
\text { Loss } \\
\text { \% }\end{array}$ & $\begin{array}{c}\text { Vickers } \\
\text { Hardness } \\
\text { (HV) }\end{array}$ & $\begin{array}{c}\text { Density } \\
\text { (g.cm-3) }\end{array}$ \\
\hline Exp_A & 6.2 & 302 & 1.37 \\
\hline Exp_B & 1.5 & 263 & 1.55 \\
\hline Exp_C & 2.3 & 345 & 1.56 \\
\hline Exp_D & 1.5 & 297 & 1.79 \\
\hline Exp_E & 20.8 & 351 & 1.22 \\
\hline Exp_F & 21.6 & 311 & 1.42 \\
\hline
\end{tabular}

Figure 21 shows a comparison of weight loss in acid for all the samples. Results for acidic medium highlight degradation among almost all the shafts. Results show clearly that shafts with 
carbon-aramid hybrid reinforcement suffered most degradation, whereas shafts with carbonglass hybrid reinforcement suffered the least. As the main component of glass fiber is $\mathrm{SiO}_{2}$, it is more stable and hence more resistant to degradation by an acid. Moreover, in terms of comparison among different type of resins, it was found that resin with high-temperature curing showed less degradation as compared to the resin with room temperature curing. This behavior is attributed to high polymerization as possessed by high temperature cured shafts. For carbon-aramid hybrid reinforcement, the behavior for both types of resins is almost similar.

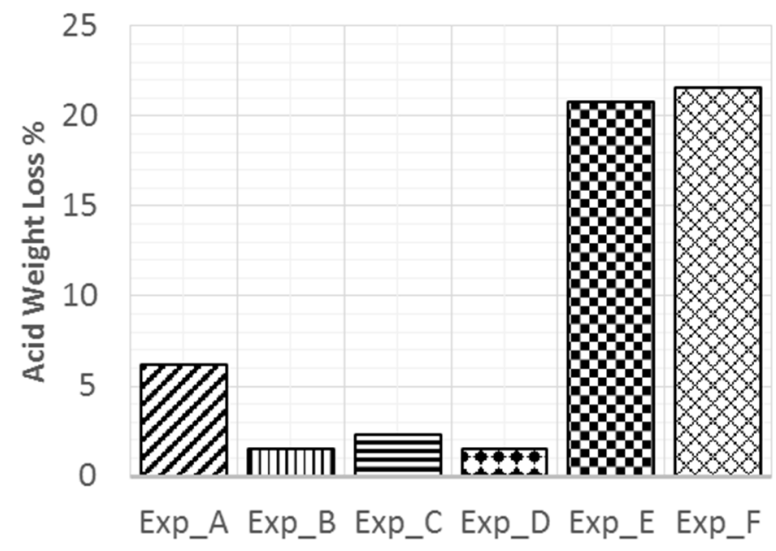

Figure 21: Graphical comparison of weight loss in acid

\subsection{Hardness}

The surface hardness of a material is the ability to resist scratch. Hardness is of prime importance when a material is used in mechanical design which included extensive moving parts. Figure 22 illustrates a comparison of hardness values.

By analyzing hardness values, it is observed that shafts with hybrid reinforcement showed higher values than shafts with carbon reinforcement. Both carbon-aramid reinforced shafts and carbon-glass reinforced shafts showed $14 \%$ better hardness than carbon shafts. For room temperature curing resin, the value for carbonaramid reinforcement is almost identical to carbon-glass aramid.

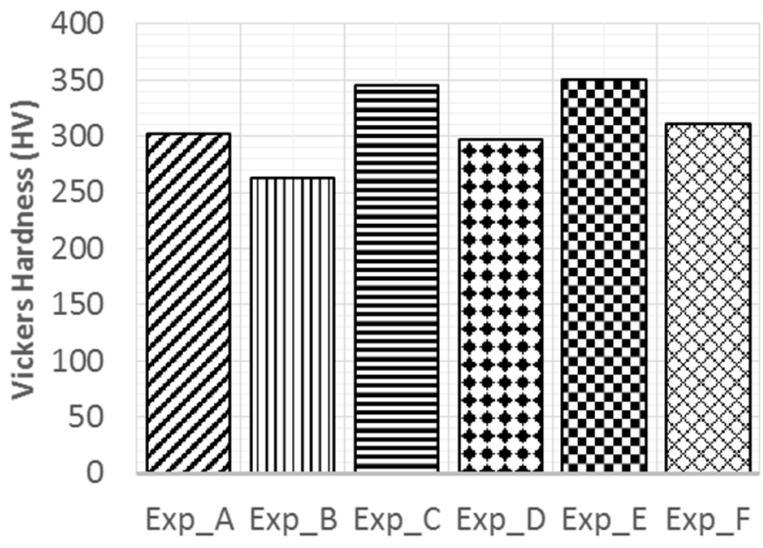

Figure 22: Graphical comparison of hardness values

Shafts with room temperature curing resin exhibit more hardness than shafts with high temperature curing resin. Room temperature cured shafts showed $13 \%, 14 \%$ and $11 \%$ more hardness for carbon, carbon-glass, and carbonaramid respectively, as compared to hot-curing resin. The reason for such performance is credited to surface thickness caused by curing shafts in an oven where heat is supplied to the surface of the shaft through convection.

\subsection{Density}

For aerospace applications, weight of the structure is a prime factor. As density correlates with the weight of the structure, it is important to analyze it before applying in airborne structures.

A comparison of the density of all samples is illustrated in Figure 23. It is revealed that carbon-aramid hybrid reinforcement shows minimum values of density, whereas carbonglass hybrid reinforcement depicts the maximum values.

Aramid fibers possess less linear density than other fibers, its hybrid also depicts the same value. Similarly, glass fibers exhibit higher density among all, the hybrid shafts with glass fibers also present the same trend. Moreover, shafts with hot-curing resin display more density than shafts with room temperature curing resin due to more density of matrix material because of more shrinkage caused during curing process. 


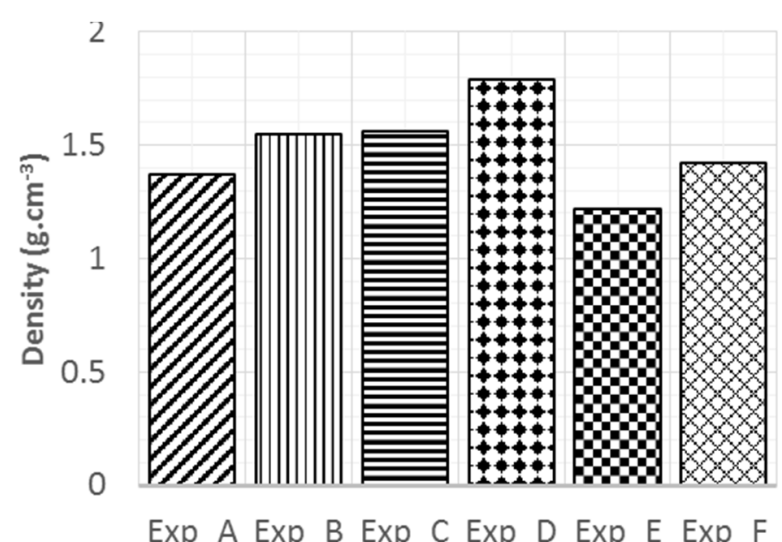

Figure 23: Graphical comparison of density

\section{Conclusions}

Composite shafts consisting of conventional and hybrid reinforcements were manufactured and tested. As the main aim of the study was to evaluate performance, torsional tests reveal that that with the use of hybrid reinforcements, the torsional strength, stiffness, and resilience decreased as compared to pure carbon shafts. For glass fiber percentage decrease in torsional properties on an average of $43 \%$ was observed whereas for aramid fiber, average $23 \%$ loss of properties was evident. While observing torsional characteristics it is concluded that shaft with only carbon fibers showed the highest values whereas carbon-glass hybrid depicted the least values. Moreover, carbon-aramid shafts showed intermediary values for torsional characteristics.

It is also concluded that with the replacement of room temperature curing resin with hot-curing resin, a decrease in torsional properties was found. Carbon-Aramid hybrid shaft showed only $8 \%$ loss of strength whereas carbon-glass hybrid and pure carbon fiber presented $17 \%$ and $15 \%$ respectively.

It is found that hybrid shafts do not degrade in saline water. Moreover, for acid reactivity tests, hybrid shafts with aramid and carbon reinforcements showed rapid weight loss. Room temperature cured resin showed most weight loss for carbon fiber reinforcements with a value of $6 \%$. Maximum weight loss was observed in carbon-aramid hybrid shafts where loss as high as $21 \%$ was recorded. Hence to conclude, composite shafts are safe to use in the saline environment but their use in the high acidic environment must be avoided.

Also, it is inferred that hybrid reinforcements had positive effects on the hardness as it increases by almost $40 \mathrm{HV}$ with the inclusion of both glass and aramid fiber with carbon fiber. Moreover, in comparison of the type of resin, room temperature cured resin exhibited more hardness than high temperature cured resin. Hence shafts with hybrid reinforcements are more resistant to mechanical wear as compared to pure carbon fiber shafts. Carbon-aramid fiber hybrid exhibited better results in terms of density and weight than other fiber types.

With an addition of aramid fiber to carbon fiber to make a hybrid, $10 \%$ weight reduction was found. Also, hot cured resin displayed average $0.2 \mathrm{~g} . \mathrm{cm}^{-3}$ more density than room temperature curing the resin. Hence to conclude, carbonAramid hybrid shafts offer low weight characteristic and can be used for airborne applications.

It is concluded that torsional properties decrease as carbon fiber shafts are hybridized with glass or aramid fibers. However, hybrid shafts can be employed in applications where a tradeoff is required between two or more properties. Glass fibers are much less costly than carbon fiber and hence carbon-glass hybrid shafts provides a relatively better performance while being cost effective. Similarly, carbon-aramid hybrid shafts shows low weight than pure carbon fiber shafts hence this class may be used for aerospace application where tradeoff between weight and torsional strength is required. Furthermore, this study provides a groundwork for designers to develop hybridized hollow shaft in such a way that two or more distinct characteristics can be addressed.

\section{References}


[1] D. Cho, D. Lee and J. Choi, "Manufacture of one-piece automotive drive shafts with aluminum and composite materials", Composite Structures, vol. 38, no. 1-4, pp. 309-319, 1997.

[2] G. Marsh, "Composite ship shafts shape up", Reinforced Plastics, vol. 45, no. 11, pp. 32-36, 2001.

[3] K. Bang and D. Lee, "Design of carbon fiber composite shafts for high-speed air spindles", Composite Structures, vol. 55, no. 2, pp. 247-259, 2002.

[4] H. Gubran, "Dynamics of hybrid shafts", Mechanics Research Communications, vol. 32, no. 4, pp. 368-374, 2005.

[5] B. Harris, "A perspective view of composite materials development", Materials \& Design, vol. 12, no. 5, pp. 259-272, 1991.

[6] E. Sevkat, H. Tumer, M. Halidun Kelestemur and S. Dogan, "Effect of torsional strain-rate and lay-up sequences on the performance of hybrid composite shafts", Materials \& Design, vol. 60, pp. 310-319, 2014.

[7] A. Abu Talib, A. Ali, M. Badie, N. Azida Che Lah and A. Golestaneh, "Developing a hybrid, carbon/glass fiber-reinforced, epoxy composite automotive drive shaft", Materials \& Design, vol. 31, no. 1, pp. 514-521, 2010.

[8] M. Badie, E. Mahdi and A. Hamouda, "An investigation into hybrid carbon/glass fiber reinforced epoxy composite automotive drive shaft", Materials \& Design, vol. 32, no. 3, pp. 1485-1500, 2011.

[9] D. Lee, H. Sung Kim, J. Woon Kim and J. Kook Kim, "Design and manufacture of an automotive hybrid aluminum/composite drive shaft", Composite Structures, vol. 63, no. 1, pp. 87-99, 2004.

[10] S. Mutasher, "Prediction of the torsional strength of the hybrid aluminum/composite drive shaft", Materials \& Design, vol. 30, no. 2, pp. 215-220, 2009.

[11] C. Capela, J. Ferreira, T. Febra and J. Costa, "Fatigue strength of tubular carbon fiber composites under bending/torsion loading", International Journal of Fatigue, vol. 70, pp. 216-222, 2015.

[12] Z. Pater, A. Gontarz, J. Tomczak and T. Bulzak, "Producing hollow drive shafts by rotary compression", Archives of Civil and Mechanical Engineering, vol. 15, no. 4, pp. 917-924, 2015.

[13] M. Shokrieh, A. Hasani and L. Lessard, "Shear buckling of a composite drive shaft under torsion", Composite Structures, vol. 64, no. 1, pp. 63-69, 2004.

[14] C. Bert and C. Kim, "Analysis of buckling of hollow laminated composite drive shafts", Composites Science and Technology, vol. 53, no. 3, pp. 343-351, 1995.

[15] S. Misri, S. Sapuan, Z. Leman and M. Ishak, "Torsional behaviour of filament wound kenaf yarn fibre reinforced unsaturated polyester composite hollow shafts", Materials \& Design, vol. 65, pp. 953960, 2015.

[16] N. Siddiqui, S. Khan, and J. Kim, "Experimental torsional shear properties of carbon fiber reinforced epoxy composites containing carbon nanotubes", Composite Structures, vol. 104, pp. 230-238, 2013.

[17] F. Beer, and E. Johnston. Mechanics of materials. New York: McGraw-Hill, 1981.

[18] Sarkar, B. (2003). Strength of materials. New Delhi: Tata McGraw-Hill. 
2017-09-06

\section{Effect of hybrid reinforcement on the performance of filament wound hollow shaft}

Tariq, Mateen

Elsevier

Mateen Tariq, Salman Nisar, Aqueel Shah, Sohaib Akbar, Muhammad Ali Khan, Sohaib Zia

Khan, Effect of hybrid reinforcement on the performance of filament wound hollow shaft, Composite Structures, Volume 184, 2018, Pages 378-387

https://doi.org/10.1016/j.compstruct.2017.09.098

Downloaded from Cranfield Library Services E-Repository 